\title{
Parental agency, identity and knowledge: mothers of children with dyslexia
}

Carol Buswell Griffiths, Brahm Norwich and Bob Burden

Revised Feb 2004

Contact Brahm Norwich:

School of Education and Lifelong Learning

University of Exeter

Heavitree Road

Exeter EX1 2LU 


\title{
Parental agency, identity and knowledge: mothers of children with dyslexia
}

\begin{abstract}
In this paper we report and analyse findings from part of a two year evaluation project which focuses on parent-professional communications over the issues of learning difficulties arising from dyslexia. The key concepts in this study are dyslexia friendly schools and parental partnership which are discussed in the current policy interest in inclusive education and parent partnership. A conceptual framework has been derived from the study which focuses on parental strategies to ensure adequate provision for their children, knowledge about dyslexia and identity, in particular that of the mother of the child with dyslexia. Excerpts from in depth interviews of parents are then presented to illustrate the framework. The significance of the findings is examined in relation to other studies of parent partnership. Implications for a more inclusive version of extended professionalism are also considered.
\end{abstract}




\section{Introduction}

We report and discuss findings from a project which has been examining the problems and issues that arise in the communication between parents and professionals over parental concerns about their children's literacy difficulties / dyslexia. The two key concepts in this project are parent partnership and dyslexia-friendly schools (DFS for short). Both have a background in education policy and practice over the last two decades, though the actual terms of reference have changed over time.

The DFS notion (BDA, 1999) has arisen from the British Dyslexia Association, a voluntary organisation which aims to support the interests of people with dyslexia. In summary, a DFS is defined as one where all teachers:

are appropriately trained,

aware of the impact of cognitive difficulties on teaching their subject,

aware of the strengths and weaknesses of individuals with dyslexia,

practice appropriate assessment which focuses on content rather than presentation,

make an effort to raise self esteem and enable the child to develop her/his strengths,

accept that parents have anxieties and are responded to positively,

- $\quad$ seek advice when face problems in responding to child with dyslexia,

DFSs also have systems in place which:

enable children to learn how best to learn,

give access to specialist teaching (balance between withdrawal and in-class support) and

give access to appropriate ICT to support learning.

Further details about how this has been put into operation in Swansea are found in Mackay (2001).

The DFS notion represents an attempt to apply the whole school special educational needs (SEN) policy approach to the field of dyslexia. A whole school approach to special educational needs has been promoted since the 1980s (for example, Thomas and Feiler, 1988). There are links between this earlier notion of how schools accommodate and respond to diverse learning needs and the more recent notion of inclusive schools. The proponents of the former continue to be proponents of the latter (Thomas et al. 1998). The notion of DFS reflects the current interest in schools that accommodate and respond to the diversity of pupils, inclusive schools, but confines its interest to those with dyslexia. This is a significant difference as inclusive schools are about accommodating all vulnerable children (see Inclusion Index - Booth et al., 2000) not just those with SEN/disabilities. This departure represents one of the recent developments in the wider SEN field, the growing emergence of interest groups focussing on medically defined areas of difficulties, e.g. dyslexia, dyspraxia, ADHD and autism. In referring to dyslexia and DFSs we are not taking a position about the nature and existence of dyslexia or dyslexic type literacy difficulties. For the purposes of this research our use of the term derives from how Government, parents, teachers and voluntary organisations use it. Its contentious nature is highlighted in the research we report here.

One of the criteria of a dyslexia friendly school is 'acceptance that parents have anxieties and are responded to positively'. So, the DFS notion is linked to the parent partnership one and this is the specific focus of this paper.

\section{Policy context}

Given the link between DFS and parent partnership, we would expect these notions to operate at 3 linked levels of analysis. At the most general level, there is parental partnership linked to 
notions of inclusive schooling. Inclusive schools are about greater participation and collaboration. Parent partnership relates at this level to all parents, not to specific groups, while inclusion covers all kinds of diversity and exceptionality, not just disability and specific areas of disability. Within this general level, there is the level concerned with SEN and disability overall. At this level parent partnership is in relation to the broad area of SEN linked to schools inclusive of all forms of disability. At the most specific level and within these two more general levels is parent partnership in relation to an interest group, such as dyslexia, linked to the notion of dyslexia friendly schools.

This analysis raises the policy question of the benefits of working with disability-specific notions like DFS over and above the broader concept of an inclusive school. There is also the linked question of the benefits of addressing issues of parent partnership for dyslexia, over and above partnership issues for all parents. These are important questions in the recent historical context where the main policy developments over the last 30 years in this country have been about partnership for all and for the diversity of SEN. Interest in the third specific level - partnership with the dyslexic group - is much more recent and is associated with the growth of disability specific interest groups. Another feature of the education policy context has been the continuing separatism of SEN policy developments from general or mainstream developments. Although there have been links between the general and SEN spheres, this separatism has been evident in the parent partnership field too.

The significance of the growth of the inclusive movement in education is the expectation that general education systems become more flexible to respond to greater diversity. Applied to parent partnership, this means that general systems become more flexible to include and subsume most partnership arrangements for SEN and dyslexia. The main principles and practices associated with home-school relations would be relevant to working with parents of children with SEN in general and dyslexia in particular. However, additional arrangements may be required for an identified minority of parents whose children have SEN. But, it is notable that the current additional arrangements, the statutory assessment and Statementing system, have come under increasing criticism. For example, it has been argued that it is costly and bureaucratic, stress inducing and alienating, not providing assurance to parents, leading to inequitable resource allocation and not supporting inclusive practices (Audit Commission, 2002). Recent Government policy also recognises that more inclusion means fewer children with Statements (OFSTED, 2002). The implication is that parent partnership be approached as much as possible starting from general arrangements, not starting from a SEN or a dyslexia perspective.

The common versus SEN-dedicated issue in parent partnership was recognised in a recent DfEE research project on partnership and SEN (Vernon, 1999). Vernon argues that promoting partnership and the planning of developments would benefit from a debate about a conceptual framework which addressed the following questions:

1. To what degree is partnership about working with parents as individuals and/or with them collectively?

2. Does partnership with parents involve working with professionals as well as parents?

3. How is partnership in SEN best promoted at school; by targeting the parents of children with SEN or by targeting the parents of all children?

Posed like this, the third question might seem to call for an either/or answer, when the preferred answer may be both. Priority could be given to focussing on all parents flexibly in a way that includes specific groups within SEN, but that additional targeting of some parents of children with SEN may also be justified in rare and exceptional circumstances. But, this dual 
approach requires a continuing interplay and convergence of ideas, values and practices between general parent partnership and SEN specific partnership.

Vernon (1999) has also noted that although the concept of partnership has been subject to little examination and analysis, there has been some convergence in general conceptions of parent partnership and those found in SEN. Pugh et al. (1987) describe partnership as:

'A working relationship that is characterised by a shared sense of purpose, mutual respect and willingness to negotiate. This implies a sharing of information, responsibility, skills, decision making and accountability.' (Pugh et al. 1987; p.5)

These authors identify parent - teacher relationships as ranging along a continuum from nonparticipation, through support, participation and partnership to control. It is clear that partnership is less than parent control and more than parent support, but the difference between participation and partnership is not clearly specified. Some time ago, Wolfendale (1983) contrasted parents as clients with parents as partners. As clients, parents are cast as dependent, passive, peripheral to decisions and potentially inadequate; as partners, they are cast as actively involved in decisions, having equivalent expertise, contribute to services and share responsibility. This resembles aspects of the Pugh's conceptions of partnership and participation, as does the earlier SEN notion from the Warnock Report (DES, 1978):

'Parents can be effective partners only if professionals take notice of what they say and how they express their needs, and treat their contribution as intrinsically important' ( DES 1978 para. 9.6, p. 151)

Similar views were incorporated in the initial SEN Code of Practice (DfE, 1994):

'The knowledge, views and experiences of parents are vital. Effective assessment and provision will be secured where there is the greatest possible degree of partnership between parents and their children, LEAs and other agencies.' (SEN Code, 1.2, p.2)

The policy development most relevant to this project was the introduction of the Parent Partnership Schemes (PPS) in 1994. These schemes were meant to encourage the development of active partnership practices, for all children with SEN, not just for children with Statements. The objectives were to provide information and advisory services, initiate the named persons scheme to reduce conflict and minimise the number of SEN tribunal appeals.

In an evaluation of these schemes, Wolfendale and Cook (1997) were very positive about the progress made in setting them up around the country. The core activities were $i$. casework with parents, ii. information and publicity services, iii. training and support and iv. network and facilitation of interest groups. However, the evaluation also showed that though the schemes promoted more informed parent participation, questions were raised about whether the PPSs addressed the professional and school end of the partnership relationships. Schools were identified as needing support to help them develop strategies to work more effectively with parents. This finding was reinforced by OFSTED reports on the implementation of the SEN Code of Practice (OFSTED, 1996, OFSTED, 1997) which found that schools were having difficulties in working with parents. The PPSs and befriender schemes were found to be relatively unknown in schools, a gap which was also identified in the SEN Green Paper (DfEE, 1997) 
In her evaluation of parent partnership in 25 schools across 6 LEAs, Vernon (1999) found parental concerns about their relationships with schools. Most of these schools recognised that they had not addressed parent partnership sufficiently, nor did many mainstream schools report initiatives targeted at parents of children with SEN. The importance of being an 'open school' to parents and seeing this as integral to the development of a whole school approach to SEN was recognised by many of the head teachers. But, this required a 'cultural change' in schools that involved a change in parental perceptions of teachers and schools and changing attitudes by professionals.

In a more recent evaluation of PPSs in Wales, (Wolfendale and Bryan, 2002), it was reported that many parents felt that they had to struggle to get information and advice. A minority of parents were positive about the support they received from schools. Schools were found to be variable in providing relevant SEN information, having parent friendly policies, in their attitudes to individual children with SEN, their openness in sharing information about child's progress and their willingness to listen to parents about home based problems.

At a national policy level, the SEN and Disability Act (2001) places a duty on LEAs to provide PP services and have regard to the guidance about this in the revised SEN Code of Practice. LEAs are required to appoint an independent person to assist in the 'resolution of disputes' between parents and LEAs and/or schools. LEAs are required to make parents aware of the PP services and the dispute prevention and resolution service. This is the current context within which this project took place.

\section{Research project and methods}

The research which we report was part of a larger project funded by the Buttle Trust and British Dyslexia Association (BDA) concerned with supporting dyslexic children in mainstream schools and building parent partnerships within the ethos of dyslexia-friendly schools. The project had two independent parts. The development work was done by a dyslexia fieldworker working in five LEA areas in the South West over two years. The fieldworker aimed to support parents who had concerns and tried to assist in resolving these through practical support and advice. Though the field worker was based in the South West she is professionally connected to, and supported by, the BDA. The research and evaluation work, which was managed separately and undertaken independently by the authors, was based at the School of Education, University of Exeter. It aimed to focus on two aspects:

1. problems and issues that arise in the communication between parents and professionals over parental concerns about dyslexia

2. an evaluation of the development work undertaken by the fieldworker and the ways in which she has supported parents.

We focus in this paper on the first of the two main aims of the evaluation study.

At the outset of the project we identified 7 families from across the 5 LEAs to comprise a short term longitudinal sample. Of these families 4 had already contacted the fieldworker with a query or problem and the other 3 had contacted the research team themselves as a result of publicity. The aim was not to obtain a representative or structured sample, rather to follow the families over a two-year period during which time old issues might be solved and new ones emerge. At the time of analysis, these families had been interviewed twice and were due to be interviewed twice more over a two year period. 
In order to evaluate the fieldwork aspect of the project 6 families who had sought help from the fieldworker were chosen in order to examine them as case studies. These families are being interviewed as are the teachers in schools that the children attend. All documentation pertaining to theses families is being collected.

This paper is based on the interviews so far conducted with the parents in both the longitudinal (7) and evaluation samples (4). All interviews have been transcribed in full and then analysed by two of the researchers independently for emergent themes relevant to parent-professional communications. From the jointly agreed themes a working conceptual framework was devised and then subjected to repeated adaptation as more data were analysed. The findings are presented in terms of the broad themes from this framework

\section{Findings}

We present the framework and then discuss its elements and their relationships with reference to data from our interviews. We identified three main inter-related themes which cover, 1. Knowledge in the field, 2. Identity of the mother of the child with dyslexia, and 3. Parental Strategies. We discuss each of these and their relationships in what follows.

Insert figure here

\section{i. Knowledge}

We identified three elements concerning the theme of knowledge, 1. kinds of knowledge, 2. the process of acquiring knowledge and 3. the mediation of this knowledge by different agencies.

\section{Kinds of knowledge}

Formal ideas about dyslexia derive from the fields of psychology, biology, medicine and education. These fields operate with different theories and practices, some of which conflict, but have in common an approach to dyslexia, which could be called 'academic'. We understand 'academic' knowledge to derive from professionals, whether working in university or professional settings. For our purposes it can be contrasted with common-sense, or lay, knowledge even though the two kinds of knowledge interact with each other over time. We assume that all kinds of knowledge in the dyslexia field become accepted, adopted, disputed and reinterpreted by educationists, voluntary groups and parents.

The disparities between academic and common- sense knowledge are evident in the frustrations that parents sometimes feel when solutions they can work out are not applied to their child. This is exemplified by an approach to a problem that they think is not being addressed, but could easily be solved. For example:

One of the things in particular was the way he got down his homework. Ifelt that they weren't getting the information in a slow enough and concise enough way for him to know what was going on, they were told just as they were going out of the door right at the end and they had to hold it and scribble it down, which he's not really that good at doing, and it puts them at a disadvantage then because they're not sure what to do, they try to phone their friends but their friends don't want them ringing constantly to ask them what the homework is, so I was very upset about that. ... I don't see any reason why the teacher can't write down, you know sort of put up the instructions and give it out to them or something. Or write it on the board at the beginning. (Mother B). 
However, it should be noted that the common-sense 'solutions' to perceived difficulties can reflect disagreements as does academic knowledge. In this case we find a contradiction between the mother and father:

Mother B: .... whereas what they might need to do is just set him a few lower targets that he can achieve so that he behaves better. See I don't see any sign of targets being set on a regular basis, I think that would make a big difference, just to have low down targets that are easy to achieve so that he can say 'I've don't it.' And the other thing, he never seems to have any homework.

Father B: Well that's the thing I was just thinking about, instead of setting him lower targets, setting him higher targets. Maybe surprise himself, and maybe it could be the other way round and say well maybe you should be giving him more so that he does have to concentrate.

\section{Acquiring knowledge}

Voluntary organisations, and their publications, are an important source of information and knowledge for parents. This is especially true with regard to 'symptoms' and, sometimes, solutions.

Mother M: I kind of got them (Dyslexia Institute) to do some work and me and Amanda went along and we did some work together and I tried to get them to teach me how to help her so we did that really so that was really helpful.... so she did lots of games with us and it was great and I kept it up while we were going up there one day a week and then I was doing stuff at home with her but I must admit I've let it lapse now..... I've done the training programme with (some community workers I know) Interviewer: So you're well connected and well informed aren't you?

Mother M: Oh yeah, I do, I make it my business 'cos nobody is going to help you, you've got to help yourself. And I'm lucky enough that I can do that, I mean most people, average parents, especially disadvantaged parents where they haven't got much money

Acquiring knowledge is also the basis of increased confidence:

We'll I'm just glad that I don't take no for an answer basically, I'm glad that I have got a brain in my head, I'm glad that I ask questions and I'm glad that once someone delivers the information and I suppose I probably should have found the information out myself but once I was given that information then I started exploring things and questioning it and not actually accepting that, you know, 'Well this is the best you're gonna get,' well is it? Who says.... (Mother G)

\section{Mediation and change of knowledge}

Contradictions in both academic and common sense knowledge open up 'spaces' in which organisations and individuals can select and, if necessary, re-construct their own knowledge framework. Here is an example of a mother who is grappling with acquiring more knowledge and understanding about her child's difficulties. She finds that a talk given by a psychologist mediates aspects not previously considered.

I'm trying to learn about his situation and about dyslexia and I feel quite a novice in respect I don't know what progress to expect...... we went to a talk on self esteem and this was quite an eye-opener for me because, it was given by one of the psychologists and he gave us things to do and we sort of, I did it, we could do it on behalf of the children basically, he said at the end what the research test was about and I did it 
and, for both of my children it appeared that they had quite a good self esteem. (Mother C)

This is an example of a mother attempting to find a way of communicating with teachers, where knowledge mediation came through paying for an individual professional consultation: She didn't want to go to school, she was really struggling and I was quite concerned and I didn't feel, I kept saying to the school..., I mean I wish I had gone on my gut feeling the year previous really.... I wasn't happy and she was so unhappy she didn't want to go to school, she was crying every morning. ... I felt she was below average with everything and just, she was just struggling.... I was concerned but they said they were happy with her progress and, but I wasn't.....School still weren't convinced there was a problem..... I don't like to rock the boat, I think oh I'll just leave it be. And the other thing is I think you always think well they're professionals, they know best, you know I felt well they don't think there's a problem, perhaps there isn't, but then I just, you know I was getting more and more concerned... I paid for the initial assessment..... Mrs $R$ put her through a range of tests and spoke to me and she said 'You know I can see, you know she's dyslexic' and you know as soon as she sort of explained things to me it all fell in to place. (Mother A)

\section{ii. Identity as a basis for agency}

We found evidence that some teachers have pedagogic and learning theories which see certain kinds of 'labelling' as having negative consequences for pupils. This leads them to regard the label of 'dyslexia' as something which would, at worst, make the child ashamed or uncomfortable or, at best, act as an excuse to hinder effort. Labels, when conferred by others in a pejorative way, may well have those effects. However, personal troubles turned into public issues, though, can affirm the validity of a positive identity (Shakespeare, 1993). In this sense, the dyslexic label has quite different meaning for many parents.

... and I said to her (teacher) 'Look, he is dyslexic,' (she said) 'You're not to put a label on him because he will not try, and if he's got a label he won't try... He won't try, labels are no good.' And I said 'Well I'm sorry but since Ben has known what's wrong with him, he's so much better.' Because bless him, he thought he was stupid, well he's not stupid (Mother D)

Some parents perceive a hierarchy of learning difficulties, with a difference between difficulties in a specific area (e.g. dyslexia) and general difficulties across different areas of learning (e.g. slow learning). This enables them to distance dyslexia from other more pervasive difficulties. The dyslexic definition and identity, therefore, serve to differentiate the dyslexic from the others in a way which has positive implications and allows them to emphasise intellectual capabilities and 'potential'. This is in contrast to the effect that certain other labels and diagnoses might have on parents and children.

The only thing we had was he used to go out with his mixed group of backwards, backward children, it was a mixed group, I remember another parent asking a question about that, it was a meeting with (...) in the Autumn term, this parent asked, because some of the children in that group have learning difficulties because they've got mental slowness but others might be a dyslexic child with a capable mind.... but the other thing was that he should have adequate tutoring in the school so that he can learn something, I mean in actual fact you don't feel, we never did feel that as a child that he was lacking in intelligence, .....(Grand mother L)

The way that dyslexia is defined also confers other positives, a 'no 
blame' identity to parents and children themselves and some hope that something can be done.

I think it all made sense to him then, that it wasn't his fault and that, 'cos he had just, as he came out of infants he was just beginning to lose the heart and feeling out of sync with his peers and feeling separate from his friends and I think having that label actually for him, and I was saying 'There's lots we can do, there's lots of help you can get' $^{\prime}$ (Mother F)

However, this hope does not automatically lead to action in particular cases:

And I suppose it explained a few things but it didn't really help because I felt if it was diagnosed or if it was given a label then automatically the help comes along but that isn't the way that it works is it? (Mother G).

Because of the strength and visibility of voluntary organisations at national and local level, the dyslexic identity can turn a private trouble into a shared issue.

I mean I've, since I've, I've had a lot of very good literature from the Dyslexia Association, I've found them to be very helpful. And it's very interesting reading up in the magazine and you realise that there is a lot of children out there with problems (Mother A)

The dyslexia diagnosis/label, if conferred by others, may often be a comforting confirmation of unarticulated worries

We had assumed it from very early on, you know from infant school through early years, so yeah it was just a relief to know. And also his behaviour wasn't that good at that point and it was going down rapidly so it was quite nice to actually be told. (Mother B)

The label and identity also offers an explanation of the reluctance of others to define and diagnose. This father explains such reluctance in terms of an unwillingness to supply appropriate teaching..

With A. people seem afraid to say the word, it's as though if they say it they've got to supply you with more.(Father A)

Sometimes the dyslexia 'community' becomes the basis for action once a help has been received on an individual basis.

I am now on the Committee of the local Dyslexia Assoc and I shall be setting up a parent help group. I have talked to other parents on the phone already. (Mother J)

Conflicting expectations

One of the differences between schools and parents is obviously that of a concern with all pupils versus concern over a single individual. This, of course, is not a feature only of parents of children with special needs, but does take increased significance and importance with this group

I talked about the SENNA programme, SENNA again to her and she said it's more for children who have kind of got a, she put it like got a mental, almost, need. And I said 'Well surely it should be available to children with additional needs, I mean it's an additional need isn't it? (Mother M) 
I'm just fighting me corner for me son 'cos I'm doing no more than what any other parent would do...., you must have come across a lot of disgruntled parents over the years who are probably more despairing than what we are and their kids might need more funding than what ours does. You know but unfortunately you've got to look after your own child, your own child to look after (Father $H$ )

\section{iii. Parental strategies}

The strategies that parents adopt, mainly mothers, escalate from an initial verbal or written concern to the school:

I was concerned but they said they were happy with her progress and, but I wasn't.....School still weren't convinced there was a problem .(Mother A)

I wrote a note in. I didn't get a response, no. But whether they took note of it, I don't know. (mother B)

One mother who had spent five years trying to get the school and teachers to accept that her son was dyslexic became worried about his lack of progress and transfer to secondary school. The school would not arrange for an educational psychologist's assessment so the mother approached the local dyslexia association. They advised her to obtain a private assessment and recommended a professional. The report diagnosed the child as severely dyslexic. At this stage the mother by-passed the school. We found this pattern of escalation to be common in our sample. There are even higher levels which parents have contacted:

I've written to the prime minister and everybody else, I went in when they decided that yes, they would re-assess Andy or they would, you know put him forward for an assessment, I went in and saw his SENCO in school cause you had to fill out a form and she had to discuss it with me which was fine. And she said to me afterwards 'You realise I did this last year, when we applied for an assessment he was turned down.' I said 'Yes I know.' And she said 'Of course it's amazing what you get if you write to the top man isn't it?' She said 'I feel sorry for the people who don't have the gumption to get on and write,' and I said 'Well look hold on a minute, it's open to any body, any body can write to any body,' I said 'I feel as though I've had to moan to try and get some help for him... But soon afterwards things started to happen. (Mother K)

There are then a series of strategies that could be described as taking the school into the home by acquiring learning materials themselves and/or paying for home tuition. When none of these familial strategies make an impact parents up the ante and attempt to gain more from the school than it seems to be giving. Paying for a private assessment by an educational psychologist is often the first stage of the increased pressure. It is at this stage that collective association becomes important and when the common identity is acknowledged

It is interesting to note that one parent in the sample completed the school-home-school circle not only by recommending the teaching materials she had tracked down herself, but also by taking the learning assistants to the local dyslexia association meetings and accompanying them on courses

I told you, didn't I, that Mrs L - the learning assistant from the schools is now coming to the dyslexia association? Next year there's a course on dyslexia-with deeper knowledge to help your child - on at the college. A few of the learning assistants from the school are going and so am I-so we'll all go together (Mother J) 
If a home-school circle is not the outcome of action then conflict is. This can take the form of legal appeals to tribunals, which is the action this mother finally took in order to have a statement issued:

But if you can't trust yourself as a person and as a parent and you can't trust the person you are entrusting your child to which is the school system then there's something wrong, and I did, I trusted it too much, and I trusted it and trusted it and trusted it until somebody gave me the information and I started questioning things and then I realised that this should have been done a long time ago(Mother G)

The ultimate breakdown of communication is exemplified by this parent, who in sheer desperation, and with little formal education herself, finally withdrew her son from formal schooling altogether. This occurred during the project. In this family the father himself had experienced dyslexic difficulties and had a very unhappy time at school.

... he (father) felt when we were sending Andy to school, that he could see what he went through when he was at school and he was all for it to be honest, to take him out, because it just got so bad. I mean the throwing up in the mornings, it just got out of hand. So David said 'Right, let's give it a go.' And he's been brilliant, he takes him off. (Mother K)

\section{Discussion}

The significance of this study needs to be seen in the context of scarcity of similar fine grained research in the dyslexia area. There have been few studies of any kind of parental perspectives and parent partnership in relation to dyslexia, as shown by a search of the British Education Index (BEI) of educational research since the 1980s.

In one relevant study on secondary provision for specific learning difficulties, Dyson and Skidmore (1994) found that most schools said that contact with parents of children with SpLD was no different from that of other parents. Our study in contrast focuses on parental perspectives and shows areas of conflict. It is interesting, as Atkin et al. (1988) pointed out years ago, research on home-school focuses on the professional rather than parent perspective.

One recent study by Riddick (1996) did focus on the parents' perspectives and had findings which were consistent with the themes we have identified. In this study of the experience of dyslexia of 22 families, she examined experiences of the identification process and parentteacher relationships. She found that when mothers were asked who first suggested that her child had dyslexia, the majority (15/22) said that they did, not teachers or other professionals. Of 17 mothers who asked the school if their child had dyslexia, 11 reported that the school was dismissive and 5 non-committal, only in one case was there agreement. Mothers reported also that the media (magazines, TV and radio) was the main source of information about dyslexia. Interviews revealed that most mothers were relieved when it was confirmed that their child was dyslexic. Over half also reported that they felt blamed by the school for their child's difficulties. Of the 12 mothers feeling blamed, most felt criticised for being overprotective or overanxious; other criticisms related to parent emotional problems, not enough done at home, children spoilt, child abroad for the year or change in school.

Like the Riddick study, all the parents in our study, except one, were mothers. This illustrates an important point that parents are not ungendered and that liaison and negotiation with schools is largely 'mother's work'; an extension of their mothering 
tasks and responsibilities.(Reay, 1998). Their identity is that of 'the mother of a child with dyslexia' with advocacy as an ongoing part of this role. A crucial component of mother's work is the emotional labour (James, 1989) of easing their child's passage and intervening when they are unhappy or anxious. It is this identity and the expectations associated with it which form the background to mothers'- and occasionally fathers'-attempts to develop strategies to alleviate their children's distress. If, as has been noted before (Brown 1999) the rights of a disabled child are 'negotiable' then who else will start the negotiations if not the mother? Negotiations with schools, teachers and LEAs are, it is maintained here, a reflection of parental strategies.

Our study also highlights some of the problems associated with the concept and value of parent partnership. These problems need to be seen in the context of changing conceptions of parent-teacher relationships. Bastiani (1987) has provided a useful analysis of the changing conceptions in terms of four models:

1. compensation

2. communication

3. accountability

4. participation

Compensation, with links to the Plowden Report in the 1960s, focused on the level of parental supportiveness of parents, with the implication that less supportive ones needed to become more supportive. This deficit model has been criticised for overlooking wider social and political influences on parents. In the 1970s the focus shifted to one of good communication between home and school. However, effective communication can be problematic when there are disagreements about the content, especially in relation to SEN, and when parents and teachers have different assumptions. When teachers consider that they are there to enlighten uninformed parents this can interfere with communications. Accountability has assumed more importance with the move towards an education service operating along more market-style principles. Despite professional doubts about this ideology, it has had the benefit of focusing attention on the experiences and demands of parents.

Bastiani's fourth model, participation, is one where the term has been defined differently. For example, Riddick (1996) interprets participation to be the same as partnership, while Pugh et al., (1987) saw partnership as involving less professional supervision and control than participation. The problems associated with the partnership model are not just conceptual and value ones, but also practical, as our study and others have shown. Partnership takes place in organisational settings in which parents and teachers work together and this requires time and funds. Both Wolfendale and Bastiani recognise that the partnership model is not supported by everyone and that current pressures in the system do not fully support its realisation.

Our data and themes about the problems in establishing constructive communications and partnerships need to be understood in terms of wider systemic and structural factors (Power and Clark, 2000). Power and Clark reject the view of schools as victims of Government imperatives and parents as marginalised victims of professional high-handed and organisational incompetence. Schools are seen as being confronted by various demands and stretched for resources. Some parents experience frustration and humiliation, with schools remaining strange to many working-class parents. In this analysis parents are seen as disadvantaged in relating to teachers who have greater status and power. This raises the prospect of equal partnership being unattainable, if professional power is based on expert 
knowledge. Wolfendale, in promoting the partnership concept, refers instead to 'equivalent expertise' which implies a complementary but different kind of expertise. This concept tries to equate what we have called common sense and academic knowledge in our framework. Our study indicates that there can be tensions between these kinds of knowledge calling into question a notion like equivalent expertise.

One of our main themes was the difference in parent and teacher expectations. This is consistent with other literature which also draws attention to the view that parents and professionals have different interests and responsibilities (Connel, 1987; Bereford and Hastie, 1996; Power and Clark, 2000). Parents are oriented to their individual children and teachers to the many and to their organisations. It has also been argued that there are class and cultural aspects which set teachers apart from some parents, in particular, working class and ethnic minorities. Crozier (1997), for example, argued that there is a class basis to different conceptions of partnership, working class tending to trust professional to 'do the job' while middle class parents tending to be more interventionist.

We endorse the concept of extended professionalism, discussed by Power and Clark (2000) as applicable to parents of children with dyslexia. In extended professionalism teachers assume that parents are concerned and interested in their children's education and that noninvolvement does not necessarily mean a lack of interest. But, we would argue that to make the concept of extended professionalism more inclusive, it would also apply to teachers' assumptions towards parents of children with SEN in general and dyslexia in specific. In a more inclusive extended professionalism teachers would be sensitive to parental concerns about their learning progress, emotional and behavioural adjustment and well being. This extended form of professionalism requires reviewing practices from the perspectives of parents, appreciating parental knowledge and responding to their concerns with sensitivity and respect. This calls for mechanisms to enable schools to review and develop their parent partnership practices. LEAs through their parent partnership services have a role to play in this as might parent organisations which represent groups of parents collectively.

\section{Conclusion}

On the basis of a series of in-depth parental interviews we have identified three key interrelated themes which we consider to be relevant to understanding the basis for more effective parent - professional partnerships. Our sample illustrates the way in which parents negotiate on behalf of their children. In particular, we have highlighted that parenting is often not the idealised, egalitarian, de-contextualised process that current policies seem to assume. Much of parental partnership is with mothers, it is gendered, and forms an additional mother's task. Educational decision-making has to be fitted into the interstices of other concerns, which is difficult if the experiences of the mothers in this study are typical. These negotiations escalate depending on the response from talking and writing to schools and teachers to going to Tribunal and opting out of the school system. Our sample is not representative, but illustrative of what can and does happen.

With regard to these escalating strategies there are two parallel tendencies to be identified. On the one hand, there is a process of knowledge gaining and sharing linked in our framework to adopting a social identity. These processes are collective or social ones. On the other hand, there is an individualised process in which the difficulty is seen as requiring a 'solution' through individual teaching and learning. The child's difficulties are seen as distinct from those of any other child, although knowledge about the difficulties and the adopted identity are social in nature. Clearly this is not a linear process as action can take place before 
knowledge and identity are adopted and will continue afterwards. So, in this sense, the collective aspect forms a backdrop and a motor to the individualisation of the sought remedies.

The developing identity of the parent, mostly the mother, as a parent with a child with additional educational needs arising from dyslexic difficulties in learning, involves taking on expectations and norms which can depart from professional ones. This has implications as we have discussed above for adopting the notion of extended professionalism. There also needs to be a recognition that labelling, which has negative connotations for educationalists, serves very real purposes for parents.

From a wider perspective, the importance of this study lies in highlighting fundamental issues relevant to all aspects of education - the organisation of learning and teaching, patterns of selection and relationships between professionals and parents (Glatter, 1997). As Slee (1997) notes, inclusive schooling for those with disabilities - what we tend to call learning difficulties in the UK - embodies the challenge of expressing the full range of human variation in school cultures which are mediated through the curriculum, pedagogy and school organisation. This is exemplified in the final quote:

I think there should be something in place whereby these children don't feel that they're a parasite or that they're not made to feel that they're a parasite within their own mainstream school, that they should feel able to have an avenue and they should feel included and they shouldn't be made to know about (...) and pence, the mechanics that's in there, I think that's totally incorrect at that age, there's too much responsibility, and you know to be told that they're a waste of resources is even worse than telling them how much the resources come to in the first place. Anything that is going to make those children feel that they're, I mean I use the word special but even then some of them don't like being called special, so they're just unique to themselves and they're valued and they have place and they have a voice (Mother $G)$ 


\section{References}

Atkin, J., Bastiani, J. and Goode, J. (1988) Listening to parents. London: Croom Helm

Audit Commission (2002) Statutory assessment and statements of SEN: in need of review? London: Audit Commission.

Bastiani, J. (1987) Parents' and teachers' perspectives on home school relations, Windsor: NFER-Nelson

BDA (1999) Achieving dyslexia friendly schools, Reading: British Dyslexia Association.

Beresford, E. and Hardie, E. (1996) Parents and secondary schools in Bastiani, J. and Wolfendale, S. (eds.) Home-school work in Britain, London: David Fulton Publishers.

Booth, T., Ainscow, M., Black-Hawkins, K., Vaughn, M. and Shaw, L. (2000) Index for Inclusion: developing learning and participation in schools. Bristol: CSIE

Brown, C. (1999) Parent voices on advocacy, education, disability and justice' in Ballard, K (ed) Inclusive Education: international voices on disability and justice London: Falmer Press

Connel, B. (1987) Families and their kids, in Bastiani J (ed.)_Parents and teachers. Windsor: NFER-nelson

Crozier, G. (1997) Empowering the powerful: a discussion of the inter-relation of Government policies and consumerism with social class factors and the impact of this on parent interventions in their children's schooling, British Journal of Sociology of Education, $18,2,187-200$

DES (1978) Special educational needs; (The Warnock Report) London: HMSO

DfE (1994) Code of practice: on the identification and assessment of special educational needs, London: DfE

DfEE (1997) Excellence for all children: meeting special educational needs. London: DfEE

Dyson, A. and Skidmore, A. (1994) Provision for pupils with specific learning difficulties in secondary schools, Report to SOED. University of Newcastle.

Glatter, R., Woods, P. and Bagley, C. (1999) Choice and Diversity in Schooling (eds.) London: Routledge

James, N. (1989) Emotional labour; skill and work in the social regulation of feelings Sociological Review 37, 1, 15-42

Mackay, N. (2001) Dyslexia friendly schools in Peer, L. and Reid, G. (eds.) Dyslexia : successful inclusion in the secondary school,.. London : David Fulton.

OFSTED (1996) The implementation of the Code of practice for special educational needs. London: HMSO 
OFSTED (1997) The SEN Code of practice: two years on. London: HMSO

OFSTED/Audit Commission (2002) LEA strategy for the inclusion of pupils with special educational needs. OFSTED/Audit Commission

Power, S. and Clark, A. (2000) The right to know: parents, school reports and parents' evenings. Research Papers in Education 15(1), 25-48

Pugh, G., Aplin, G., De'Ath, E. and Moxon, M. (1987) Partnership in action. London: NCB

Reay, D. (1998) Class Work London: UCC Press

Riddick, B. (1996) Living with dyslexia. London: Routledge

Shakespeare, T. (1993) Disabled people's self-organisation: a new social movement?

Disability, Handicap and Society 8(3) pp249-264

Slee, R. (1997) Imported or important theory? Sociological interrogations of disablement and special education British Journal of Sociology of Education 19, 407-420

Thomas, G. and Feiler, A. (1988) Planning for special needs : a whole school approach.

Oxford : Blackwell.

Thomas, G., Walker, D. and Wenn, J. (1998) The making of the inclusive school. London:

Routledge

Vernon, J. (1999) Parent partnership : perspectives on developing practice. Research Report RR162. London: NCB/DfEE

Wolfendale, S. (1983) Parental participation in children's development and education. New York: Gordon and Breach Science.

Wolfendale, S. and Cook, G. (1997) Evaluation of special educational needs parent partnership schemes. DfEE Research report RR34

Wolfendale, S. and Bryan, T. (2002) Evaluation of SEN parent partnership in Wales, 2001. Wales, National Assembly of Wales: NASEN.

Young, M.F.D. (1971) Knowledge and control: new directions for the sociology of education (ed). London: Collier-Macmillan 


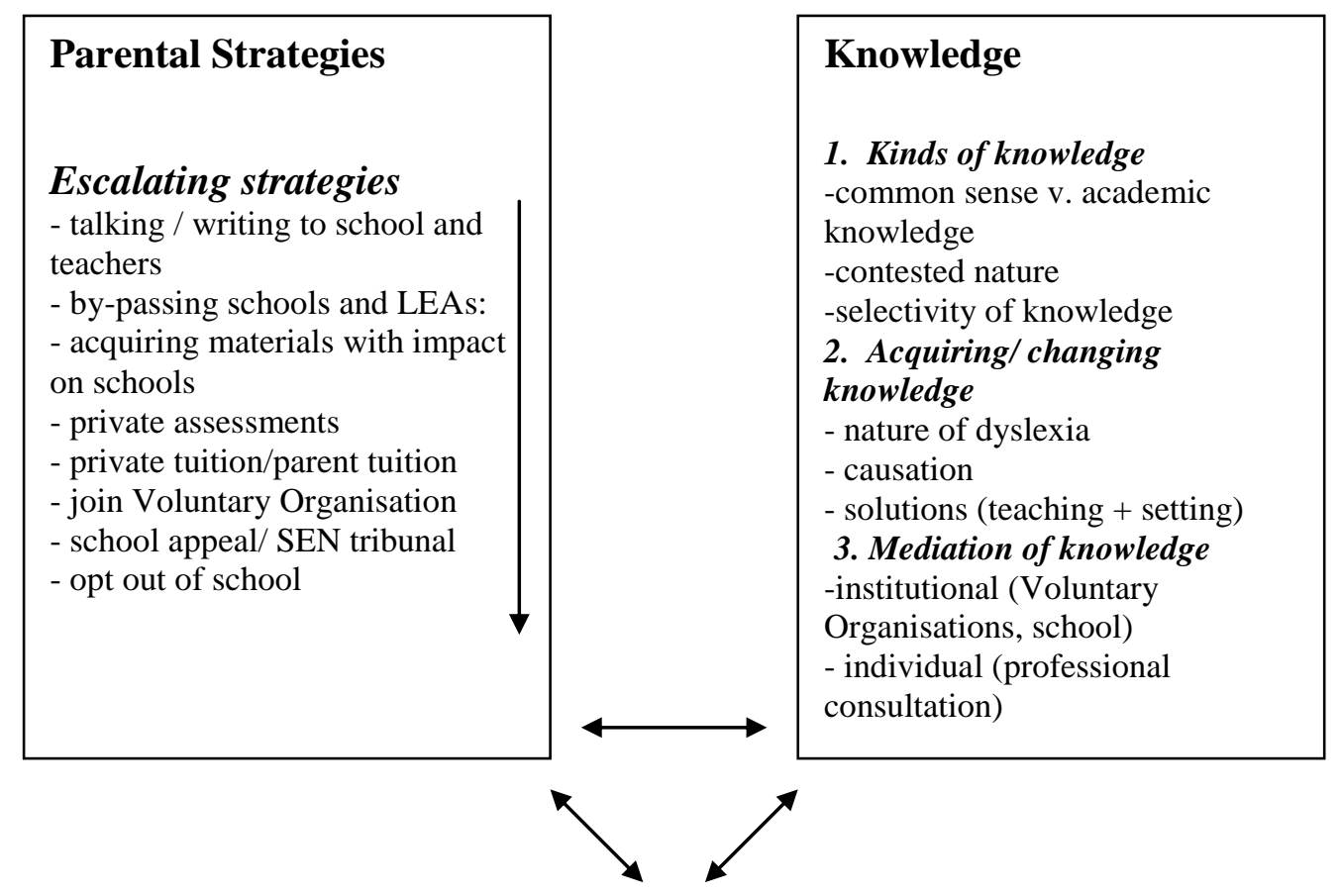

\section{Identity: mother of child with dyslexia}

Expectations / norms

- parent v. teacher

- individual child $v$ one of many

- solution seeking v. fear of labelling. 